\title{
The Obesity Epidemic: The Effect of Pre-existing Lifestyle on Attitude to the Ad, Attitude to the Brand, and Purchase Intention
}

\author{
Lynda Maddox ${ }^{1}$, Anthony Patino ${ }^{2}$, Lea Katsanis ${ }^{3}$, Dennis Pitta ${ }^{4, *}$ \\ ${ }^{1}$ School of Business, George Washington University, Washington, D. C., United States \\ ${ }^{2}$ School of Management, San Francisco University, San Francisco, United States \\ ${ }^{3}$ John Molson School of Business, Concordia University, Canada \\ ${ }^{4}$ Merrick School of Business, University of Baltimore, United States \\ *Corresponding Author: dpitta@ubalt.edu
}

Copyright $\bigcirc 2017$ by authors, all rights reserved. Authors agree that this article remains permanently open access under the terms of the Creative Commons Attribution License 4.0 International License

\begin{abstract}
The worldwide obesity epidemic has prompted governments, NGO's, and companies to explore the use of advertising to promote healthy eating habits. The effect of product or issue involvement often moderates the effects of advertising on brand image. Advertising that involves a sensitive topic, namely a person's weight, runs the risk of a consumer backlash that may tarnish a brand's image. Previous research by the authors who investigated message structure in advertising to promote healthy eating found there was no significant difference between one-sided and two-sided messages on Attitude to the $\mathrm{Ad}$ (Aad) and Attitude to the Brand (Ab). The present study assesses the effect of pre-existing eating habits on attitudes toward healthy eating after exposure to advertising. The research offers evidence that advertising disclosure can promote healthier eating. However, the effects are not straightforward. When the information confirms previous perceptions, consumers will pay more attention to it. However, consumers who have a healthy life style may not be as positively affected by the information as those whose lifestyle is less healthy and have an interest in improving it.
\end{abstract}

Keywords Attitude to the Brand, Obesity, Attitude to the Ad, Purchase Intention, Lifestyle

\section{Introduction}

Obesity remains an intractable problem in the developed world. Advertising is often blamed for the problem because food advertisers have promoted their products' taste and convenience, which may sacrifice healthiness. 'Fast food' has become synonymous with unhealthy diets and their negative effect on consumers. As an example, the rate of obesity in America has doubled in the last forty years. The
National Health and Nutrition Examination Survey (NHANES) [1] from 1960-1962, reported that 31.5\% of Americans age 20 and over were overweight or obese. In the later 2007-08 NHANES study, $68.3 \%$ of Americans age 20 and over were overweight or obese.

Modern dietary habits and their effects on weight have led to blaming the food industry for the undesirable changes in consumption trends (Dooley, Deshpande, and Adair) [2]. Despite attempts to combat obesity by including nutrition information and by public policy initiatives, obesity persists and leads to other health issues. Although advertising can be a significant first step in the formation of marketing communications (Shimp [3]; Smith and Swinyard [4]), its effectiveness and stability are not guaranteed.

\subsection{Theoretical Framework}

Previous research has shown mixed effects of advertising in efforts to reduce obesity. For example, Etgar and Goodwin [5] found that two-sided messages increase purchase intentions. More recent studies indicate that two-sided ads are not always more persuasive than one-sided ads (Crowley and Hoyer [6], Eisend [7]). Furthermore, while presenting product shortcomings and negative claims may increase source credibility, it can affect attitudes and purchase intention negatively (Crowley and Hoyer [6]).

\subsubsection{Attitudes toward the Ad and the Brand}

Research on advertising and marketing communication influences on consumer behavior is extensive. Lutz [8] defined attitude toward the ad (Aad) as a unidimensional construct "a predisposition to respond in a favorable or unfavorable manner to a particular advertising stimulus during a particular exposure occasion" (Lutz [8], p. 46). 
Multiple studies have documented the significant explanatory power of attitude toward the ad (Batra and Ray [9]; Cacioppo and Petty [10]; Lutz and MacKenzie [11] Lutz, MacKenzie and Belch [12]; MacKenzie, Lutz and Belch [13]).

The separate construct, attitude toward the brand $(\mathrm{Ab})$ is defined as an "individual's internal evaluation of the brand" by Mitchell and Olson ([14], p.318). Spears and Singh [15] augmented this definition with a more complete version stating, "attitude toward the brand is a relatively enduring, unidimensional summary evaluation of the brand that presumably energizes behavior" (p. 227). The attitudes consumers hold toward a given advertisement have been linked to their attitudes toward the brand and ultimately to purchase intentions (MacKenzie and Lutz [16]).

Burton et al. [17] indicated that the type of claim in an advertisement is crucial in the effect it has on consumer attitudes and purchase intentions. They emphasize two types of claims that focus on nutrient issues: nutrition information and verbal. The nutrition information type focused on the truthfulness of nutrition claims and the level of nutrition. Claims with higher levels of specificity and information may generate more favorable attitudes in consumers (Burton, Andrews, and Netemeyer [18]). Burton et al. [17] also explored the interaction between ad disclosure and ad claim type. They found that specific claims have more favorable effects on $\mathrm{Ab}$ when compared to general claims.

Eisend [7] also concluded that attitudes toward the ad and brand are significantly enhanced in the case of increased negative information. The negative information will not have the favorable effect on the Aad and Ab when the amount of negative information passes the consumer's threshold and the effect of two-sided messages may not differ compared with the effect of one-sided messages. The presentation of negative attributes in the beginning or at the end of an ad may have effects on consumer evaluations of the source, brand and message. Placing negative attributes at the beginning causes consumers to process further positive messages in a biased manner, and the expected favorable effects on attitude measures and purchase intentions may decrease (Pechmann [19]). Regardless of attitude toward the ad, due to the strong relationship between the attitude toward the brand and purchase intentions, it is expected that more negative information will have the same effect on purchase intention.

Considerable evidence supports the theory that negative information in ads reduces the positive effects of positive information (Pechmann [19], Bohner, Einwiller, Erb and Siebler [20]; Florack et al. [21]). However, there remains room for further understanding of the effect of such information on attitudes and further behaviors. It is still unresolved whether providing more information in the ad is helpful in the process of decision-making, or whether it simply drives consumers away from making optimal decisions.

\subsubsection{Purchase Intentions}

Attitudes are precursors to behavioral intention; in other words, the personal tendency to buy the brand or product known as purchase intention (PI) (Bagozzi and et al. [22]). Based on previous work on attitudes, exposure to the ads may lead to both favorable attitudes towards the product and ultimately, purchasing the product.

Purchase intention and attitude toward the brand have been widely studied due to their popularity and applicability. In addition, they have found a strong relationship between brand attitudes and purchase intentions.

Past studies suggest that the relation between attitude toward the object and behavior is not always observable. In some cases, attitudes have a direct effect on behaviors (Bagozzi and Warshaw [23]), while in others they do not (Bagozzi [24]) Spears and Singh [25] considered them to be related, and thus they evaluated this relationship within the Aad framework. This framework is based on several consumer behavior studies (Burke and Edell [26]; MacKenzie and Lutz [27]). In this framework, while Aad is influenced by positive and negative feelings, it affects $\mathrm{Ab}$. Positive and negative feelings also affect $A b$, which ultimately has an impact on PI.

In general, nutrition and health-related claims have been shown to have a strong effect on purchase intentions and behavior, since they directly affect how consumers value the product and what perceptions they have about the product (Drichoutis et al. [28]). Shine et al. [29] suggested that the reason for this changing behavior is that consumers want to avoid harmful ingredients in the food. Wansink and Chandon [30] found that providing "low-fat" labels raised consumption up to $28 \%$ compared to the regular-fat product. Moreover, Burton et al. [19] concluded that there are significant differences when calories are disclosed, especially in a negative disconfirmation manner. This counters the typical consumer's preconception about the food product and this disclosed caloric information lowers purchase intention.

Wansink and Chandon [30] concluded that for normal-weight people, low-fat labeling increases the consumption of foods that are perceived as healthy; for overweight people, this increases their consumption of all foods. Many other claims or labels may provide the similar ambiguity with respect to nutrition information and are important to consider, such as the context of fast food advertising. Information without educating consumers may not lead to behavioral change; the resulting ambiguity may lead to unfavorable outcomes for both the consumer and company (Teisl et al. [31]).

\subsubsection{Synthesis of Theoretical Foundations}

Consumers seek food based health information by reading labels and paying attention to health disclosures. Research on affirmative disclosures has shown mixed 
effects. Crowley and Hoyer [6] concluded that presenting negative attributes increases source credibility and consumer trust. In contrast, Eisend [7] emphasized that negative messages may have a negative effect on consumers' perception of the product and may negatively affect intention to purchase.

Consumers have been shown to change their attitudes toward the ad and brand as a result of nutrition claims and affirmative disclosures. Providing negative information about the product alongside the positive points favorably affects consumer's evaluations (Eisend [7]). However, it is uncertain whether providing positive and negative information together is effective. Drichoutis et al [28] stated that disclosing health-related claims has a strong effect on purchase intentions since these claims directly influence consumers' concerns about healthy eating and avoiding harmful ingredients.

Although it is stated that disclosing negative information may have favorable effects on attitudes and evaluations, whether it leads to a purchase decision or not is still unproven. This research attempts to clarify the different effects of affirmative disclosures in fast food ads and whether different types of affirmative disclosures have distinct effects on attitudes toward ad and brand and purchase intentions.

\section{Materials and Methods}

\subsection{Methodology/Approach}

\subsubsection{Participants and Design}

This study is a follow up to previous research investigating fast food brands perceived as healthy and unhealthy. Data was drawn from 100 participants, collected online by iResearch and participants were randomly selected and US Census stratified.

A 2 (Disclosure: no disclosure vs. disclosure) $\times 2$ (Healthy lifestyle: healthy vs. unhealthy) $\times 2$ (Fast food: Subway [healthy fast food] vs. Burger King [unhealthy fast food]) was used to assess the effect on proposed hypotheses.

Thirty-one percent of the participants were neutral with regards to adopting a healthy lifestyle and excluded from the final analyses. After excluding them, $8 \%$ were in the Low (unhealthy) category and $61 \%$ in the High (healthy) category. The unequal sizes of the two samples were controlled for using SPSS to conduct the analysis.

In the initial study, there was no significant effect of fast food (healthy or unhealthy) on Aad, Ab or PI. None of the hypotheses was accepted.

\subsection{Considerations: Healthy Lifestyle}

Two conflicting goals are noticeable when consumers make food consumption decisions: the hedonic goal of enjoying the taste of food and the utilitarian goal of following a healthy lifestyle (Dhar and Simonson [32]; Fishbach, Friedman, and Kruglanski [33]). Allocating the priority to hedonic goals leads the consumer to choose the tastier, less healthy, option over the healthier, less tasty one in the menu and would moderate the effects of advertising and affecting the brand image of the advertised product (Srivastava and Kamdar [34], Park and Young [35]).

Subjects with a healthy lifestyle differ fundamentally from those who maintain an unhealthy lifestyle. Body Mass Index (BMI) can be considered as one of the indicators of healthy life style, as Chou, Grossman, and Saffer [36] have concluded. Increase in fast food consumption contributes to increase in actual Body Mass Index (BMI). Also, Wansink and Chandon [30] indicated that for normal-weight people, low-fat labels only increase the consumption of healthy food; but for overweight people, it increases the consumption of all foods.

Based on outcome expectations as described in social-cognitive theory (Bandura [39]), the belief that certain decisions help in accomplishing personal goals is part of an individual's motivation (Desrochers and Maddox [40]). Although some consumers may have the desire to maintain a healthy weight and follow healthy dietary habits, not all consumers agree on the desirability of the goals. Those who show lower interest in maintaining a healthy weight may not pay attention to health disclosures and not be motivated by them.

\subsection{Questionnaire Development}

The scale for "adopting a healthy lifestyle" (HL) is a combination of statements that show how likely the consumer will follow a healthy lifestyle in eating or not. There are several scales developed for measuring healthy eating habits. Some of these scales come with a measure of "healthy" of "unhealthy" practices like eating breakfast (Steptoe and Wardle, [41]; Monneuse et al, [42]; Wardle et al, [43]). But they do not provide a comprehensive assessment of dietary habits. While previous work developed a comprehensive scale for measuring adult fat-related eating habits as well as fiber-related eating habits the scales' weak points used questions that focused on specific situations. From 1994-96, the Diet and Health Knowledge Survey [44] remedied earlier instrument shortcomings, and the items used in this questionnaire are drawn from that nationwide survey.

This variable measures how likely it is for a respondent to use certain nutrients with questions like "I plan to avoid foods that contain too much fat," "I plan on using sugar only in moderation," "I plan to avoid foods that contain too much salt or sodium," and "I plan to choose a diet with plenty of fruits \& vegetables". This variable was measured using a 5-point Likert scale: very unlikely, unlikely, neutral, likely and very likely. The "Adopting Healthy Lifestyle" variable was an 11-item construct with a high Cronbach 
alpha $(\alpha=0.96, M=40.74, S D=10.46)$.

\subsection{Hypotheses}

Pre-existing conditions are important in health care in general, and obesity research. The focus of the research is to determine the effect of different eating habits on consumers' attitude toward the ad and brand. Based on subjects' differing goals (Stewart and Martin [45]), the importance and effectiveness of disclosure may be greater for the consumers who perceive more benefits from eating healthy and place higher importance on healthy eating habits (Desrochers and Maddox [40]). As Burton et al. [46] also concluded, there are significant differences when disclosed information confirms previous perception about food. Consumers who adopted healthy lifestyles pay more attention to the disclosures and nutrition labels; but since choosing healthy fast food is a part of their lifestyle, they are not as positively affected by the new disclosed information as those who follow moderate or unhealthy eating habits.

Focusing on healthy versus unhealthy fast food, the following hypotheses were proposed:

$\boldsymbol{H}_{1 a}$. The use of health disclosures leads to more favorable attitudes toward the ad for healthy and unhealthy fast food. $\boldsymbol{H}_{1 b}$. The use of health disclosures leads to more favorable attitudes toward the brand for healthy and unhealthy fast food.

$\boldsymbol{H}_{1 c .}$. The use of health disclosures leads to more favorable purchase intentions for healthy and unhealthy fast food.

Two further sets of hypotheses were developed that connected consumers' stated importance for a healthy lifestyle with $\mathrm{Aad}, \mathrm{Ab}$, and PI as well as the effect of disclosure on $\mathrm{Aad}, \mathrm{Ab}$, and PI.

$\boldsymbol{H}_{2 a}$. The greater the importance of following a healthy lifestyle for participants is, the more positive their attitude toward the ad.

$\boldsymbol{H}_{2 b}$. The greater the importance of following a healthy lifestyle for participants is, the more positive their attitude toward the brand.

$\boldsymbol{H}_{2 c}$. The greater the importance of following a healthy lifestyle for participants is, the more positive their likelihood of purchase.

\section{And}

$\boldsymbol{H}_{3 \boldsymbol{a}}$. The effect of disclosure on attitude toward the ad is greater on consumers who lead on unhealthy lifestyle.

$\boldsymbol{H}_{3 a}$. The effect of disclosure on attitude toward the brand is greater on consumers who lead on unhealthy lifestyle.

$\boldsymbol{H}_{3 a}$. The effect of disclosure on purchase intention is greater on consumers who lead on unhealthy lifestyle.

\subsection{Preliminary Analysis}

\subsubsection{Data Reduction}

Factor analysis was undertaken for data reduction. The analysis revealed that some items cross-loaded on two or more factors on each of the three variables, Aad (2 factors), $\mathrm{Ab}$ ( 2 factors), and PI ( 3 factors). Details are omitted here due to space considerations. Healthy lifestyle items loaded on one factor and the factor explained $73.873 \%$ of total variance.

\subsection{Main Analysis - Model and Hypothesis Testing}

The $2 \times 2 \times 2$ two-way ANOVA analysis was conducted with disclosure, fast food and healthy lifestyle as the three variables. The analysis yielded no significant effect of disclosure on Aad, Ab or PI choice of fast food had no significant effect.

\subsection{Findings}

There was no significant effect of fast food on Aad, Ab, or PI so none of the hypotheses $\boldsymbol{H}_{1 a}, \boldsymbol{H}_{1 a}$, or $\boldsymbol{H}_{1 c}$ were confirmed (Table 1).

There was no significant interaction between healthy lifestyle and fast food or disclosure. However, consumers with healthy lifestyles had a greater Aad, Ab and PI. This group recorded a higher score on Aad, Ab and PI for both the disclosure and no disclosure condition. The effect of affirmative disclosure was significant for one of the $A b$ factors (Competitive healthiness $\mathrm{F}=9.721, \mathrm{p}=.003$ ) and one factor of PI (Healthiness of decision $\mathrm{F}=7.773, \mathrm{p}=.007$ ). The effect of healthiness of lifestyle is significant on Aad, $\mathrm{Ab}$ and PI (all p-values $<0.04$ ).

Those who follow a healthy lifestyle have a higher score on Aad and $\mathrm{Ab}$; however, those who have an unhealthy lifestyle show greater difference between the two conditions of disclosure and no disclosure. For Purchase Intentions, the healthy lifestyle group did not demonstrate great difference between disclosure and no disclosure.

Interestingly, in the unhealthy lifestyle group, affirmative disclosure has a different effect on purchase decision for healthy and unhealthy fast food. Although disclosures have a favorable effect for healthier fast food (Subway), for unhealthier fast food (Burger King) it decreases the purchase decision. Even more interesting is that on the contrary disclosures have a negative effect on healthiness of purchase decision for healthy fast food while they have a favorable effect on unhealthier fast food. In other words, participants who follow a healthy lifestyle have higher scores in attitude toward the ad, brand and purchase intentions; those who do not follow a healthy lifestyle expressed greater change in their $\mathrm{Aad}, \mathrm{Ab}$ when exposed to health disclosure compared to no disclosure. The results are reported in Table 1. 
Table 1. ANOVA results for Fast Food (F-Values)

\begin{tabular}{|c|c|c|}
\hline & Fast Food & P-value \\
\hline \multicolumn{3}{|l|}{ Effect on Aad } \\
\hline & 0.209 & 0649 \\
\hline \multicolumn{3}{|l|}{ Effect on Ab } \\
\hline Relationship to Brand & 0.417 & 0.521 \\
\hline $\begin{array}{l}\text { Competitive } \\
\text { Healthiness }\end{array}$ & 1.715 & 0.195 \\
\hline \multicolumn{3}{|l|}{ Effect on PI } \\
\hline Purchase Decision & 2.451 & 0.123 \\
\hline $\begin{array}{l}\text { Healthiness of } \\
\text { Decision }\end{array}$ & 0.401 & 0.529 \\
\hline Search Behavior & 1.52 & 0.698 \\
\hline
\end{tabular}

Additional analysis was conducted for further confirmation of the first ANOVA. Since in the first ANOVA results there was no significant effect of fast food, another ANOVA was conducted with only two other independent variables, disclosure and healthiness of lifestyle. The results are reported in Tables 2 and 3 .

The results of the second analysis show no significant effects of disclosure on Aad, and mixed effects on $\mathrm{Ab}$ and PI. Overall, hypothesis $H_{2 a}$ was not confirmed. It is interesting that effects of disclosure on elements of $\mathrm{Ab}$ and PI were significant but $H_{2 b}$ and $H_{2 c}$ were not confirmed.

There was a significant effect of healthy lifestyle on Aad, $\mathrm{Ab}$ and PI. Unhealthy lifestyle participants showed a greater change in Aad and $\mathrm{Ab}$ when exposed to health disclosures. Those with a healthy lifestyle do not show the effect of disclosure. Those with an unhealthy lifestyle express a great change in their competitive healthiness when exposed to disclosure compared to no disclosure. However, those who follow a healthy lifestyle also have a more favorable Aad, Ab and PI when exposed to disclosure. Competitive healthiness and healthiness of decision are significantly affected by disclosure and healthiness of lifestyle. Unhealthy lifestyle participants show a slightly greater change on PI.

Table 2. ANOVA results for Disclosure (F-Values)

\begin{tabular}{|c|c|c|}
\hline \multicolumn{2}{|c|}{ Disclosure } & P-value \\
\hline Effect on Aad & 2.930 & 0.092 \\
\hline \multicolumn{2}{|c|}{} \\
\hline $\begin{array}{c}\text { Effect on Ab } \\
\text { Brand }\end{array}$ & 3.137 & 0.081 \\
\hline $\begin{array}{c}\text { Competitive } \\
\text { Healthiness }\end{array}$ & 16.201 & $0.000^{* *}$ \\
\hline Effect on PI & 1.700 & 0.197 \\
\hline $\begin{array}{c}\text { Purchase Decision } \\
\text { Healthiness of } \\
\text { Decision }\end{array}$ & 4.920 & $0.030^{*}$ \\
\hline \begin{tabular}{c} 
Search Behavior \\
\hline
\end{tabular} & 0.370 & 0.545 \\
\hline
\end{tabular}

Table 3. ANOVA results for Healthy Lifestyle (F-Values)

\begin{tabular}{|l|c|c|}
\hline & Healthy Lifestyle & P-value \\
\hline \multicolumn{2}{|l|}{ Effect on Aad } \\
\hline \multicolumn{2}{|l|}{} \\
\hline Effect on Ab & 6.754 & $0.012^{*}$ \\
\hline Relationship to Brand & 7.077 & $0.000^{* *}$ \\
\hline $\begin{array}{c}\text { Competitive } \\
\text { Healthiness }\end{array}$ & 22.791 & $0.000^{* *}$ \\
\hline Effect on PI & \\
\hline $\begin{array}{c}\text { Purchase Decision } \\
\text { Healthiness of } \\
\text { Decision }\end{array}$ & 9.017 & $0.004^{* *}$ \\
\hline Search Behavior & 6.588 & $0.002^{* *}$ \\
\hline
\end{tabular}

The results of the second analysis show a significant effect of healthy lifestyle on Aad, Ab and PI. Thus $H_{3 a} H_{3 b}$ and $H_{3 c}$ are confirmed. The main model is significant for Aad, $\mathrm{Ab}$ and two factors of PI (all p-values< .04). Unhealthy lifestyle participants showed a greater change in Aad and $\mathrm{Ab}$ when exposed to health disclosures. Those with a healthy lifestyle do not show the effect of disclosure. Those with an unhealthy lifestyle express a great change in their competitive healthiness when exposed to disclosure compared to no disclosure. However, those who follow a healthy lifestyle also have a more favorable Aad, Ab and PI when exposed to disclosure. Competitive healthiness and healthiness of decision are significantly affected by disclosure and healthiness of lifestyle. Unhealthy lifestyle participants show a slightly greater change on PI.

\section{Conclusions}

\subsection{Theoretical Implications}

The results broadly support Burton et al.'s [19] contention that when disclosed information confirms previous perceptions, consumers pay more attention to the disclosures and nutrition labels. In this case, those who live a healthy lifestyle will attend to disclosures but will not be as positively affected by the information as those who follow moderate or unhealthy eating habits.

\subsection{Practical Implications}

The research offers some evidence that disclosure can promote healthier eating. In this sample, a small minority had an unhealthy lifestyle and showed an interest in improving their eating habits. Reaching them is perhaps more important than confirming the healthy eating habits of others. This group may benefit more than others by exposure to advertising. The obesity problem has been resistant to proposed solutions. Perhaps efforts to reach the most vulnerable consumers (the unhealthy lifestyle group) may bear fruit. 


\subsection{Limitations}

The middle group who value neither a healthy nor unhealthy lifestyle were omitted from analysis. They represent a larger segment than the other two. A question that remains about this group is whether advertising disclosure can prompt group members to see the value in greater interest in healthy activities.

Further limitations include the exploratory nature of the study and the small size of the resulting sample.

\subsection{Originality/Value}

Many studies have investigated the effects of advertising on Aad, Ab, and PI. Many have used student or convenience samples. This study used a consumer sample that mirrored the US population. In addition, it provides new evidence that consumers who have an unhealthy lifestyle may be reached by carefully designed advertising.

\section{REFERENCES}

[1] National Health and Nutrition Examination Survey Data. Prevention CDC. Hyattsville, MD: US Department of Health and Human Services, (2009).

[2] J. Dooley, S. Deshpande, C. Adair, Journal of Business Research., Vol. 63 Issue 2, 154-160, (2010).

[3] T. Shimp, Attitude toward the ad as a mediator of consumer brand choice. Journal of Advertising, Vol.10, No.2, 9-48, (1981).

[4] R. Smith, and W. Swinyard, Information Response Models: An Integrated Approach. Journal of Marketing, Vol. 46, No. 1, 81-93, (1982).

[5] M. Etgar., and S. A. Goodwin, One-sided versus two-sided comparative message appeals for new brand introductions. The Journal of Consumer Research, Vol. 8, No 4, 460-465, (1982).

[6] A. E. Crowley, and W. D. Hoyer, An integrative framework for understanding two-sided persuasion. Journal of Consumer Research, 561-574, (1994).

[7] M. Eisend, Two-sided advertising: A meta-analysis. International Journal of Research in Marketing, Vol. 23, No. 2, 187-198, (2005).

[8] R. J. Lutz, R. J. Affective and cognitive antecedents of attitude toward the ad: A conceptual framework. Psychological Processes and Advertising Effects, 45-63, (1986).

[9] Batra, R., \& Ray, M. L. (1986). Affective responses mediating acceptance of advertising. Journal of Consumer Research, 234-249, (1986).

[10] J. T. Cacioppo and R. E. Petty Communication and persuasion Central and peripheral routes to attitude change, New York, Springer-Verlag, (1986).
[11] R. J. Lutz, and S. B. MacKenzie, Construction of a diagnostic cognitive response model for use in commercial pretesting. Straight Talk about Attitude Research, Michael J. Naples and Joseph S. Chasin, Eds., Chicago: American Marketing Association, 144, 152, (1982).

[12] R. J. Lutz, S. B. MacKenzie and G. E. Belch. Attitude toward the ad as a mediator of advertising effectiveness: Determinants and consequences. Advances in Consumer Research, Vol. 10, No. 1, 532-539, (1983).

[13] S.B. MacKenzie R. J. Lutz. and G. E. Belch. The role of attitude toward the ad as a mediator of advertising effectiveness: A test of competing explanations. Journal of Marketing Research, 130-143, (1983).

[14] A. Mitchell, and J. Olson, J. Are product attribute beliefs the only mediator of advertising effects on brand attitude? Journal of Marketing Research, Vol. 18 (August), 318-332, (1986).

[15] N. Spears, and S. N. Singh, Measuring attitude toward the brand and purchase intentions. Journal of Current Issues \& Research in Advertising, Vol. 26, No. 2, 53-66, (1986).

[16] S. B. MacKenzie, R. J. Lutz, and G. E. Belch. The role of attitude toward the ad as a mediator of advertising effectiveness: A test of competing explanations. Journal of Marketing Research, 130-14, (1986).

[17] S. Burton, J.C. Andrews, and R. G. Netemeyer, Nutrition ad claims and disclosures: Interaction and mediation effects for consumer evaluations of the brand and the ad. Marketing Letters, Vol 11, No.3, 235-247, (2000).

[18] S. Burton, E. H. Creyer, J. Kees, and K. Huggins, Attacking the obesity epidemic: The potential health benefits of providing nutrition information in restaurants. Journal Information, Vol. 96, No. 9, (2006).

[19] C. Pechmann. Predicting when two-sided ads will be more effective than one-sided ads: The role of correlational and correspondent inferences. Journal of Marketing Research, 441-453, (1992).

[20] G. Bohner, S. Einwiller, H. Erb, and F. Siebler. When small means comfortable: Relations between product attributes in two-sided advertising. Journal of Consumer Psychology, Vol. 13, No. 4, 454-463, (2003).

[21] Arnd Florack, Simon Ineichen, Rahel Bieri, The impact of regulatory focus on the effect of two-sided advertising. Advances in Consumer Research. Vol. 35, 947-949, (2008).

[22] R. P. Bagozzi, A.M. Tybout, C.S. Craig, and B. Sternthal. The construct validity of the tripartite classification of attitudes. Journal of Marketing Research, 88-95, (1979).

[23] R. P. Bagozzi and P.R. Warshaw. An examination of the etiology of the attitude-behavior relation for goal-directed behaviors. Multivariate Behavioral Research, Vol. 27, No. 4, 601-634, (1992).

[24] R. P. Bagozzi. The self-regulation of attitudes, intentions, and behavior. Social Psychology Quarterly, 178-204, (2004).

[25] N. Spears, and S. N. Singh, Measuring attitude toward the brand and purchase intentions. Journal of Current Issues \& Research in Advertising, Vol. 26, No. 2, 53-66, (2004). 
[26] M. C. Burke, and J.A. Edell. The impact of feelings on ad-based affect and cognition. Journal of Marketing Research, 69-83, (1989).

[27] S. B. MacKenzie, R. J. Lutz. An empirical examination of the structural antecedents of attitude toward the ad in an advertising pretesting context. The Journal of Marketing, 48-65, (1989).

[28] A. Drichoutis, P. Lazaridis, and R. M. Nayga. Consumers' use of nutritional labels: A review of research studies and issues. Academy of Marketing Science Review, Vol. 10, No. 9, (2009).

[29] A. Shine, S. O'Reilly, and K. O'Sullivan. Consumer use of nutrition labels. British Food Journal, Vol. 99, No. 8, 290-296, (1995).

[30] B. Wansink, and P. Chandon, Slim by design: Redirecting the accidental drivers of mindless overeating. Journal of Consumer Psychology. (2014).

[31] M. F. Teisl, N.E., Bockstael, and A. Levy, Measuring the welfare effects of nutrition information. American Journal of Agricultural Economics, Vol. 83, No. 1, 133-149, (2001).

[32] R. Dhar, and I. Simonson, Making complementary choices in consumption episodes: Highlighting versus balancing. Journal of Marketing Research, Vol. 36, No. 1, (1999).

[33] A. Fishbach, A., R. Friedman, and A. Kruglanski, Leading us not into temptation: Momentary allurements elicit overriding goal activation. Journal of Personality and Social Psychology, Vol. 84, No. 2, 296, (2003).

[34] Srivastava, M., \& Kamdar, R. M. (2009). "Brand Image Formation as a Function of Involvement and Familiarity." Paradigm, Vol 13, No. 1, 84-90, (2009).

[35] C. Park, and S. Young, Consumer Response to Television Commercials: The Impact of Involvement and Background Music on Brand Attitude Formation." Journal of Marketing Research, Vol. 23, No. 1, 11-24, (1986).

[36] S. Chou, M. Grossman, and H. Saffer,. An economic analysis of adult obesity: Results from the behavioral risk factor surveillance system. Journal of Health Economics,
Vol. 23, No. 3, 565-587, (2004).

[37] B. Wansink, and P. Chandon. Can" low-fat" nutrition labels lead to obesity? Journal of Marketing Research, Vol. 43, No. 4, 605-617, (2006).

[38] A. Bandura. Social Foundations of Thought and Action: A Social-Cognitive View. Englewood Cliffs, NJ: Prentice-Hall, (1986).

[39] A. Bandura, Self-efficacy: The exercise of self-control. Gordonsville, VA: WH Freeman \& Co. (1997).

[40] D. Desrochers, D. and L. Maddox, Effects of health guidelines on fast food restaurant advertising. II. International Conference on Communication, Media, Technology and Design 02-04 May, (2007).

[41] A. Steptoe, and J. Wardle, Motivational factors as mediators of socioeconomic variations in dietary intake patterns. Psychology \& Health, Vol.14, No. 3, 391-402, (2001).

[42] M. Monneuse, F. Bellisle, and G. Koppert, Eating habits, food and health related attitudes and beliefs reported by French students. European Journal of clinical nutrition, Vol. 51, No. 1, (2016).

[43] J. Wardle, J. Griffith, F, Johnson, and L. Rapoport, Intentional weight control and food choice habits in a national representative sample of adults in the UK. International Journal of Obesity \& Related Metabolic Disorders, Vol. 24, No. 5, (2005).

[44] U.S. Department of Agriculture, 1994-96 Diet and Health Knowledge Survey. National Technical Information Service, Springfield VA, (1998).

[45] D. Stewart, and I. Martin,. Advertising disclosures: Clear and conspicuous or understood and used? Journal of Public Policy and Marketing, Vol. 23, No. 2, 183-192, (2004).

[46] S. Burton, E. Howlett, and A. Tangari, Food for thought: How will the nutrition labeling of quick service restaurant menu items influence consumers' product evaluations, purchase intentions, and choices? Journal of Retailing, Vol..85, No. 3, 258-273, (2009). 